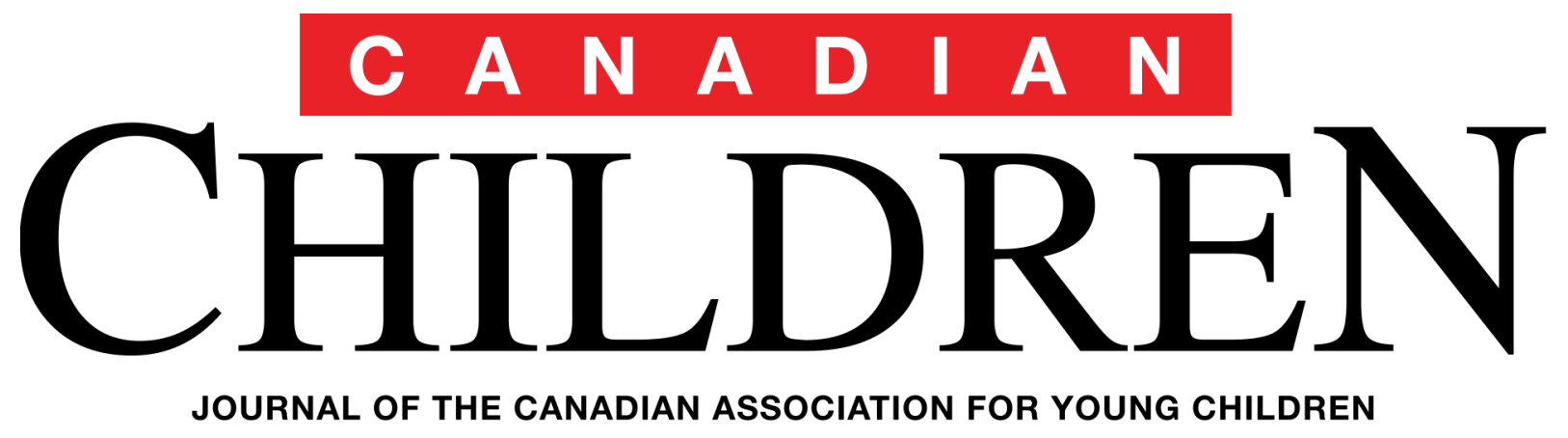

Winter 2014 / Hiver 2014

Vol. 39 No. 1

\title{
From the Editor's Desk
}

Special Issue: Neoliberalism

Dr. Luigi Iannacci, Trent University, Peterborough, Ontario

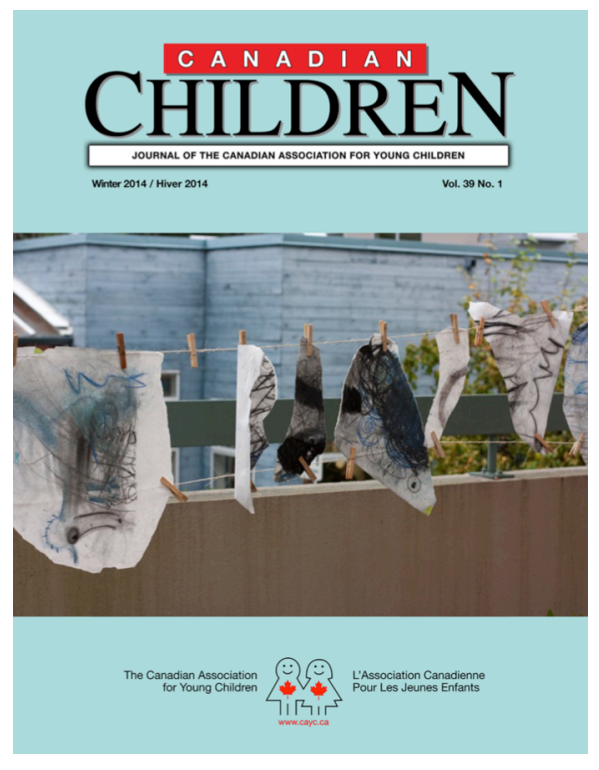

Editors:

Dr. Laurie Kocher, Douglas College, Coquitlam, British Columbia Dr. Veronica Pacini-Ketchabaw, University of Victoria, Victoria,

British Columbia

Guest Editor, Special Issue: Neoliberalism

Dr. Luigi Iannacci, Trent University, Peterborough, Ontario

Publications Chairperson:

Dr. Iris Berger, University of British Columbia, Vancouver, British Columbia

Cover Photo:

Dr. Sylvia Kind

(C) 1996: The Canadian Association for Young Children ISSN: 0833-7519

Author Guidelines: visit www.cayc.ca 


\title{
Canadian Children
}

JOURNAL OF THE CANADIAN ASSOCIATION FOR YOUNG CHILDREN

Volume 39 Number 12014 [page 1 to 2]

www.cayc.ca

\section{From the Editor's Desk Special Issue: Neoliberalism}

\author{
Guest Editor, Dr. Luigi Iannacci \\ Trent University, Peterborough, Ontario
}

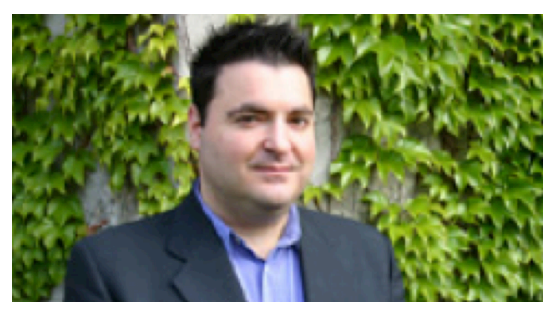

\begin{abstract}
Author's Bio
Luigi Iannacci is Associate Professor in the School of Education and Professional Learning at Trent University in Peterborough, Ontario. He is the editor (with Pam Whitty) of Early Childhood Reconceptualist Perspectives (2009, Detselig Press) and author (with Rachel Heydon) of Early Childhood Curricula and the De-Pathologizing of Childhood (2008, University of Toronto Press).
\end{abstract}

There are inherent dangers in critically exploring a dominant narrative such as neoliberalism as it concerns any field, context or case. Theorizing events and activity as being "the result of" or "due to" over arching conceptual/socio/political/economic apparatus such as neoliberalism can fail to recognize the infinite actors and factors that mediate how neoliberalism is taken up as people and things interact alongside it as opposed to because of it.

Concern for avoiding this danger informed the call that asked potential authors to consider submitting their work for this "Neoliberalism in ECE" themed issue of Canadian Children. Authors were asked to consider how neoliberal assemblages can create both possibilities and limitations within ECE. This was not suggested as a way to ensure validation of neoliberalism or "good news" stories within the papers but rather to ask that contradictions and contextual specificity be fully considered to offer readers a complex exploration of neoliberalism as it relates to ECE. 
The carefully crafted articles authors submitted and offered in this issue provide this complexity and have in every way avoided causal claims and surface theorizing. All of the papers successfully illustrate how neoliberalism has shifted and expanded well past its original legacy of privatization, deregulation and social provision reduction (Harvey, 2005) to becoming a way of knowing and being. As such, this issue as a whole demonstrates a complexified and pluralized understanding of neoliberalism as it relates to Canadian ECE.

The issue is timely as ECE within Canada has become more governmentalized than ever and tensions between early childhood education, care and schoolification continue to mount. These tensions are not quelled or considered problems to be solved in this issue but rather addressed in critical ways that show the intricacies of neoliberalism in the everyday lives of children and those who care for and teach them.

As guest editor of this issue I am looking forward to readers of Canadian Children having the same opportunity I had to learn from these papers. I want to thank all of the authors for being dedicated teachers and communicators. The papers have forwarded and challenged my thinking. I want to also thank Laurie Kocher and Veronica Pacini-Ketchabaw (Editors of Canadian Children) for inviting me to be guest editor of this special issue and for all of their guidance and support throughout the process.

\section{$\sim$ Luigi Iannacci}

\section{Reference}

Harvey, D. (2005). A brief history of neoliberalism. New York: Oxford University Press. 


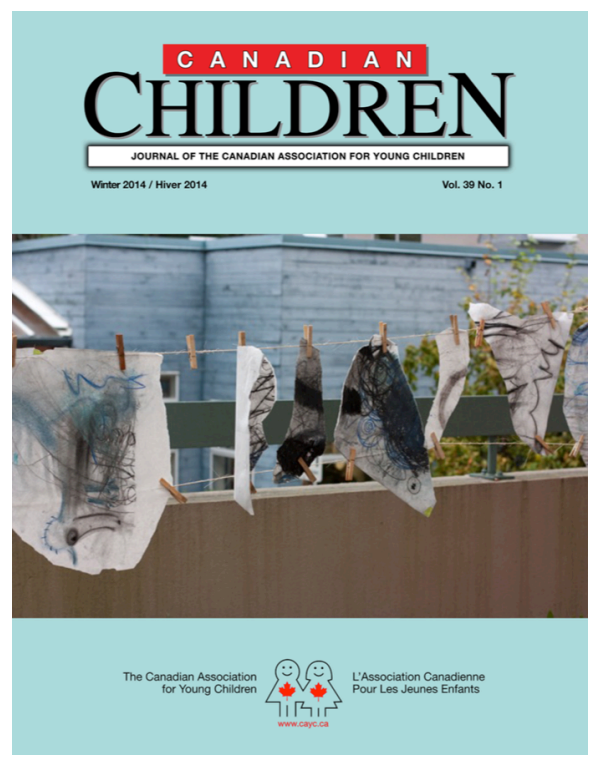

\section{In this issue:}

From the Editor's Desk

Special Issue: Neoliberalism

Guest Editor Dr. Luigi Iannacci, PhD, Trent University,

Peterborough, Ontario

I've got my EYE on you:

Schooled Readiness, Standardized Testing, and Developmental Surveillance

by Emily Ashton

Bear-Child Stories in Late Liberal Colonialist Spaces of Childhood by Veronica Pacini-Ketchabaw, Lara di Tomasso, Fikile Nxumalo

Producing Neoliberal Parenting Subjectivities:

ANT-Inspired Readings from an Informal Early Learning Program by Rosamund Stooke

Neoliberal Fun and Happiness in Early Childhood Education

by Cristina D. Vintimilla

Radical Education and the Common School:

A Democratic Alternative

by Michael Fielding and Peter Moss

Reviewed by Kim Atkinson

Call for Contributions:

'The Visual Arts in Early Childhood Education'

Find other articles from this issue at www.cayc.ca 